\title{
Samuelson's Model of Money with n-Period Lifetimes
}

$\sqrt{1}$

- AUL SAMUELSON'S OVERLAPPING genera. tions model is a classic in modern economic literature. It has enjoyed a renaissance in the last decade or so as a framework for analyzing fundamental issues in many areas of economics, including pure theory, public finance and, of special concern for this paper, monetary theory. Samuelson's (1958) model continues to attract interest in the latter field because it has the potential to offer a convincing explanation of why unbacked paper currency has value without resort to special assumptions. ${ }^{2}$ This paper will focus on the value of paper currency in a generalized version of Samuelson's original approach.

Samuelson's essential insight was to introduce demographic structure. The economic actors in the model actually die, so that people have finite planning horizons even though the economy itself continues without end. This is in stark contrast to the immortal people that occupy the chief rival models in use in macroeconomics today, most of which are sophisticated versions of growth models pioneered by Ramsey (1928) and Solow (1956). Yet, while these rivals in the 1980s have begun confronting the data directly, the overlapping generations approach for the most part remains the province of theorists. ${ }^{3}$ This is so primarily because a "time period," instead of being interpretable as a month or a quarter, has a biological basis as a fraction of an adult human lifetime; in standard two-period formulations, it would be interpreted literally as something on the order of 25 or 30 years. Conventional data sets preclude most empirical analysis on such a time scale. This fact forms the foundation for a great deal of criticism of the overlapping generations approach.

The purpose of this paper is to argue that some of the key results from conventional over. lapping generations models in which agents live for two periods extend surprisingly well to the case where agents live for many periods-at least for the example studied here. Consequently, some of the typical criticisms of Samuelson's model of money should exert less force on economists than they commonly do. In addition, the $n$-period approach opens the possibility,
1 See, for instance, Walace (1980).

2 Special assumptions that have been used include placing money in the utility function, or imposing a cash-in-advance constraint on the purchase of some goods. For discussions of these alfernative approaches, see Sargent (1987).
${ }^{3}$ See Kydland and Prescott (1982) for an example of comparing the predictions of a Ramsey-Solow model with data. 
already pursued by some researchers, of confronting overlapping generations models with available data from macroeconomic time series.

Recent general theoretical results on $n$-period overlapping generations models are developed in Kehoe, et al. (1991) and Aiyagari (1988, 1989). ${ }^{4}$ This paper illustrates some key points developed by these authors. Some results are new, however, especially those concerning the conditions for fiat currency to have value in equilibrium.

In particular, previous studies have suggested that, if the people in the model discount the future, letting the number of periods in the model become arbitrarily large implies that fiat money cannot be valued in equilibrium. ${ }^{5}$ Since most economists believe that people in real economies do discount the future, this result seemed to sink hopes that the overlapping generations approach could convincingly explain why unbacked paper currency has value. The results presented here suggest, in contrast, that discounting the future is actually less important than the previous research seemed to suggest. The condition for fiat currency to have value in equilibrium in the $n$-period model is instead found to be analogous to the condition in the two-period model. In fact, there is a sense in which adding periods to a model with discounting makes it easier, instead of more difficult, to satisfy the condition.

Whether fiat currency has value in equilibrium also depends on the lifetime productivity profiles of the economic actors in the model ${ }^{6}$ A standard result from the two-period model is that this profile would have to be declining over a person's lifetime in order for fiat currency to be valued in equilibrium. ${ }^{7}$ In actual economies, however, productivity tends to rise with age, dropping off quickly only near retirement. A key result of the present paper is that in the $n$-period model fiat money can still be valued when the lifetime productivity profile is plausibly hump-shaped.
The results described above, it should be emphasized, are based entirely on an example in which the preferences of the people in the model are described by particularly simple func. tions. ${ }^{*}$ This allows key results to be derived algebraically. The model will be described in the following section. The results concerning the existence of stationary equilibria and the conditions for fiat currency to be valued are described subsequently, and will be contrasted and compared to the conventional two-period case.

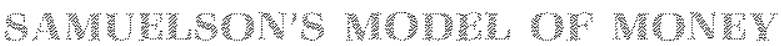

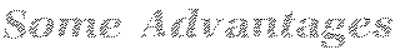

Given a disturbing disadvantage such as an inappropriately long time period, one might wonder if retaining the overlapping generations framework is worthwhile. But Samuelson's approach has important advantages that have induced continuing interest in the model, time period problems notwithstanding. A fow of these positive aspects will be reviewed here.

In Samuelson's model, a new generation is born in every period, at the same time that the oldest generation dies. This structure implies a certain heterogeneity among individuals, where younger people have a relatively long horizon in which to work and save, and older people have a relatively short horizon. One can infer that this will affect the way these people behave. Although heterogeneity of this type is a feature of observed economies, it is absent from most competing models. ${ }^{9}$

As has already been emphasized, fiat money intrinsically worthless pieces of paper issued by the government-can have value in equilibrium in Samuelson's model without resort to special assumptions. This is the primary reason monetary theorists have paid close altention to the model. In contrast, the Ramsey-Solow model generally does not admit equilibria with valued fiat money unless special assumptions are invoked.

\footnotetext{
4 Strictly speaking, the Kehoe, et al. (1991) results apply to "large square economies," that is, those with many goods and many participants, but where consumers live for only two periods. However, they argue that, analytically speaking, these models are equivalent to those with, say, a single good and $n$-period lifetimes.

5 This is an oversimplification; more exact statements will be made in the next section.

${ }^{6}$ These are represented by the endowment patterns in the subsequent analysis.
}

7This is also an oversimplification, the meaning of which will be clatified in the discussion of the model.

${ }^{8}$ People will be endowed with logarithmic, time-separable utility functions.

9 There are some models in which all people have infinite lives but heterogeneity of a similar type plays a role. See, for instance, Becker and Foias (1987). 
There are two stationary equilibria in conven. tional versions of Samuelson's two-period. model. ${ }^{10}$ One is the monetary steady state, where fiat currency has value and the price level is constant (provided the currency stock is constantl. The other is the autarkic (no trade) steady state, where fiat currency has no value (currency is not held) and the price level grows without bound. One concern about n-period versions of the overlapping generations model has been that the number of stationary equilibria might multiply uncontrollably as $n$ increased to a value that would allow researchers to interpret a time period as, say, a quarter. Presumably, if one thinks of adult lifetimes as 55 or 60 years, $n$ would have to be 220 or 240 for such an interpretation to be valid. It is therefore somewhat surprising that the version of the n-period model examined here has only two stationary equilibria, and that these are the analogs of the two steady states that exist when $n=2 .{ }^{11}$

The fact that two steady states can exist is important, because the conventional overlapping generations model also serves as a classic example of a framework that may produce inefficient equilibria. ${ }^{12}$ The monetary steady state can be an improvement (that is, everyone in the model can be made better off over the autarkic equilibrium. Therefore, the introduction of fiat currency by the government can represent a welfare-improving intervention. Hence, there is scope in Samuelson's model for a discussion of a policy role for the government-another contrast with generic versions of the Ramsey-Solow model. An analysis of welfare will not be undertaken in this paper, however.

\section{Sompris}

Many critics of Samuelson's model have argued that the two-period lifetime assumption, or aspects related to it, make it an unsatisfactory model of money. One critic is Tobin (1980), who lists several reasons why, in his opinion, the two-period overlapping generations model is a "parable," not a serious model of money. Among
Tobin's reasons is that identifying money as an asset that would be held for 25 years is "slightly ridiculous," in part because "the average holding period of a dollar of demand deposits is about two days." He also suggests that the real world analog of the asset in the model might be better viewed as land. Social security schemes, in 'Tobin's view, would be better mechanisms for accomplishing intergenerational transfers between the old and the young. In short, the "money" in the overlapping generations model, according to Tobin, "is not the money of common parlance." Since all of these criticisms are tied to the notion that the time period in the model is very long, an n-period model in which the period could be much shorter, but could share conclusions similar to the two-period model, presumably would allay some of these concerns.

Another aspect of the time period problem and its treatment in the literature deserves mention. Some authors have argued that many of the central insights would carry over from the two-period case to the $n$-period case and that, for clarity's sake, the two-period model should be the version of choice. Thus, Mccallum (1983) asserted that "some properties of twoperiod overlapping generations models will carry over to versions in which a larger number of phases of life are recognized." Similarly, Friedman and Hahn (1990) state that

[Olverlapping generations models are both more robust and more interesting than is sometimes believed.... Of course, the postulate of two-period lives is highly unrealistic. On the other hand, it is difficult to think of a qualitative conclusion of these models ... that is plausibly at risk from more realistic life times... There may ... be a difference in qualitative conclusions as one passes from finitely to infinitely lived agents. It takes, however, a peculiar perception of the world to regard the latter as the more "realistic" approach. ${ }^{33}$

From this perspective, it is valuable to find out to what extent such assertions are correct,

\footnotetext{
19 Stationary equilibria will be defined in the next section.

11 More general versions of this result can be found in Kehoe, et al. (1991).

12 That is, there may be Pareto suboptimal competitive equilibria.

${ }^{13}$ Friedman and Hahn (1990), p. xiv. Italics in original.
} 
and thus to what extent two-period models can be viewed as elegant representations of $n$-period models. ${ }^{14}$

\section{A

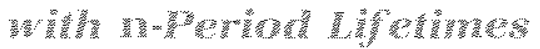

The model economy that will be studied in this paper endures forever. ${ }^{35}$ It consists of agents who live for a fixed number of periods and are endowed at each of these dates with various amounts of a consumption good. The model economy consists only of these endowmentsthere is no production. ${ }^{36}$ The agents have a government that endures forever. A new gener. ation of agents is born each period, at the same time the oldest generation dies.

The agents make decisions about how much to consume and save. There are $a=1 \ldots q_{t}$ agents within a generation, so that $q_{1}$ is the population size of the generation born at lime $t$. Population sizes of gelnerations born in previous periods are denoted by $q_{t \sim 1}, q_{t-2}, \ldots q_{t-n+1}$, where $n \geq 2$ is the number of periods in an agent's life. The total population alive at time $t$ is given by $\sum_{j=\{1}^{7 n-1} q_{n-j}$. The (exogenously given) gross rate of population growth is denoted by $\alpha$, so that $\sum_{j=0}^{\operatorname{Tan} 1} q_{i \cdots j}=\alpha \sum_{j=1}^{i n} q_{i-j}$

An agent born at time $f$ is said to be "of generation $t . "$ Birth dates are denoted by subscript time. ${ }^{17}$ The single consumption good is perishable, so that agents are unable to store it for future sale. The endowments of agent a of generation $t$ are denoted by $w_{t}^{(t)}$ at lime $t$, $w^{a}(t+1)$ at time $t+1, \ldots$, and $w_{t}^{a}(t+n-1)$ at time $t+n-1$. Endowments cannot be negative. Lifetime consumption of agent a of generation $t$ is denoted by $c^{a}(t), c^{a}(t+1), \ldots, c^{a}(t+n-1)$.
'The agents pay lump sum taxes (receive transfers if $\tau>0)$ of $\tau_{t}^{a}(t), \tau(t+1), \ldots, \tau_{t}^{a}(t+n-1)$. After-tax endowments, defined as endowments less taxes, are denoted by $\tilde{w}_{t}^{a}(t), \tilde{w}_{t}^{a}(t+1), \ldots$, $\tilde{w}_{i}^{a}(t+n-1)$. Later in the analysis, these taxes will be set to zero, but for now they serve to motivate a role for government. The agents are not connected in any way; they care only about their own lifetime consumption and they do not leave bequests to future generations. ${ }^{18}$

The market for loans is the heart of this model economy. Agent a of generation $t$ could borrow from or lend to agents in the same cohort or the government. In addition, an individual agent could borrow from or lend to agents in other cohorts living at date $t$, except for the agents that are in their last period of life. Because those agents will die, they will not be able to fepay debts or collect loans-hence, they will not participate in the loan market. The government could lend or borrow on a multiperiod basis, instead of limiting itself to oneperiod instruments, even when agents live for only two periods. For instance, a young agent might buy a multiperiod bond from the govermment, even though the maturity date is beyond the agent's lifetime, because there may be a secondary market in bonds. Similarly, mulliperiod loans could exist in the private market, either because both agents involved will be alive for the duration of the contract or because a secondary market exists for private loans. Despite all of these possibilities, the loan market in this paper will be restricted to one. period contracts. This assumption is made for two reasons. One is that, in the twoperiod version of this model, the existence of multiperiod government bonds does not change the analysis. The other is simply a desire to keep the discus: sion focused. ${ }^{19}$

\footnotetext{
14 Many authors have considered modifications of the overlapping generations approach in order to reinterpret the time period in the model or avoid the time period problem altogether. See, for instance, Blanchard (1985) and Wood. ford (1989). Some authors have worked directiy on extending verstons of the averiapping generations model to a large number of periods, although not usually with money included. A prominent example is the work of Auerbach and Kotlikoff (1987), who have simulated 55-period models, interpreting the time period as a year, in order to analyze fiscal policies. Altig and Caristrom (1991) have used a similar strategy to analyze certain aspects of monetary policy. Their model does not include fiat currency via the standard approach. Rios-Rul (1991) calibrates an $n$-period overlapping generations model without money.

${ }^{15}$ That is, time in the model runs from the infinite past to the infinite future.
}

${ }^{16}$ Considerable literature exists on overlapping generations models with production, but this paper is limited to a discussion of endowment economies.

17 The notational convention used throughout this paper is that subscripts denote birthdates, while parentheses denote real time. For an exposition of the two-period model in similar notation, see Sargent (1987).

${ }^{18}$ Bequest motives and storage, both of which are ignored in this paper, are studied in detail in the literature on twoperiod overlapping generations models.

15 See McCandless and Wallace (1991) for a discussion of multiperiod bonds in a two-period model. 
An agent is said to save (supply loans) in a particular period if the after-tax endowment in that period plus previous period savings and interest, less consumption in that period, is nonzero. The agent has no incentive to save in the $n^{\text {th }}$ period of life, since death occurs in period $n+1$, but may elect to save in any other period of life. The savings of agent a of generation $t$ is denoted by $l_{t}^{a}(t)$ at time $l, l_{i}^{a}(t+1)$ at time $t+1$, and so on up to $l_{t}^{a}(t+n-2)$ at time $t+n-2$.

In order to find the aggregate savings in the economy at a point in time, it is easiest to look at the amounts each living generation is saving at that point in time. These amounts are given by

$\sum_{a=1}^{q_{t}} l_{t}^{a}(t)=\sum_{a=1}^{t_{t}}\left[\tilde{w}_{t}^{a t}(t)-c_{t}^{a}(t)\right]$

for generation $t$, and

$\sum_{a=1}^{q_{1}} l_{j}^{a}(t)=\sum_{a=1}^{q_{j}}\left[\tilde{w}_{j}^{z}(t)-c_{j}^{a}(t)\right]+R(t-1) \sum_{a=1}^{q_{1}} l_{j}^{a}(t-1)$

for generation $j$, where $j=t-1, \ldots, t-n+2$. Aggregate savings at time $t$ is the sum of these sums weighted by the relative size of each generation. Since the population growth rate is exogenous and constant, the size of the time $t-1$ generation relative to the size of the time $t$ generation is $1 / \alpha$. In this paper, the convention is adopted that the date $t=0$ generation has size one. Therefore, aggregate savings can be written as

(1) $S(t)=\sum_{j=0}^{n-2} \alpha^{t-j} l_{t-j}(t)$

Much of the subsequent analysis will be in terms of aggregate savings.

The government makes purchases of $G(t) \geq 0$ units of the good and collects the lump-sum taxes of $\tau_{t}^{a}(t)$ from agent a of generation $t$ at time $t$. The government lends $L^{g}(t)$ (borrows if $L^{g}(t)$ is negative) via one-period loans at time $t$. Government loans are repaid $R(t) L^{g}(t)$ at time $t+1$, where $R(t)$ is the gross rate of interest on loans at time $t$. The government also holds $H(\mathrm{t})$ $>0$ units of paper currency at time $t$.
The price in currency units of the single good at time $t$ is denoted $P(t)$. The government budget constraint is given by

$$
\begin{gathered}
G(t)+L^{g}(t)=\sum_{j=t-n+1}^{t} \sum_{i=1}^{q_{j}} t_{j}^{a}(t)+R(t-1) L^{g}(t-1) \\
+[H(t)-H(t-1)] / P(t) .
\end{gathered}
$$

This equation states that government purchases plus government lending (borrowing) must be equal to previous lending phus interest earned (borrowing less interest paid), plus total taxes collected at date $t$, plus seigniorage revenue.

Arbitrage requires that the rate of return on loans is equal to the rate of return to holding currency, that is, $R(t)=P(t) / P(t+1) .^{20}$ Loan market equilibrium requires that

$S(t)=H(t) / P(t)-L^{g}(t)$

in other words, aggregate savings is equal to real money balances less government lending or borrowing.

Denoting real per capita government indebtedness as

$h(t)=\frac{H(t) / P(t)-L^{g}(t)}{\sum_{j=0}^{n-1} q_{t-j}}$

and the per capita deficit as

$d(t)=\frac{G(t)-\sum_{j=t-n+1}^{t} \sum_{d_{a=1}}^{q_{j}} t_{j}^{a}(t)}{\sum_{j=1}^{t-1} q_{t-j}}$

the model can be written as a two-equation system:

(2) $h(t)=\frac{S(t)}{\sum_{j=0}^{n+t} q_{t-j}}$

(3) $h(t)=\frac{R(t-1)}{a} h(t-1)+d(t)$.

The right-hand side of equation 2 is per capita savings. The system described by equations 2 and 3 can be written as

${ }^{20}$ This assumption causes the rate of return on two riskless assets, loans to the government and currency, to be equal. In actual economies, currency is dominated in rate of return by atternative riskless assets. Eliminating this problem would require that additional features be added to the model. Those features will not be pursued in this paper. 
(4) $S(t)=R(t-1) S(t-1)$

if $d(t)=0$ at every date $t$. This is the equation of concern in the remainder of the paper.

Fixing the deficit, if not to zero, at least to a constant, is a common way to proceed in analyzing this system when $n=2$. The usual interpretation of a fixed deficit is that this provides a way to analyze outcomes holding fiscal policy constant.

Sargent's (1987) definition of equilibrium will be employed:

Definition An equilibrium is a set of infinite sequences for population, endowments, taxes, consumption, private loans, interest rates, government expenditures and government loans such that

(i) Given a sequence of interest rates, the consumption allocation and the loan amounts satisfy the agent's maximization problem,

(ii) The government budget constraint is satisfied,

(iii) The loan market clears.

As the introduction emphasized, the value of fiat currency is the primary focus of this paper. Because of this focus, government loans, government purchases and taxes will be set to zero for the remainder of the analysis. The term $h(t)$ is then the real value of currency holdings per capita, and is equal to aggregate savings per capita. Government loans, government purchases and taxes have been included up to now to illustrate that the extension of the model to $n$ periods does not depend on setting these variables to zero. For many purposes, such as the analysis of tax effects, one might want to set $H$ equal to zero instead. That would be a model without currency. The derivation of the aggregate savings function $S(t)$ in the next portion of the paper would be equally valid for that model.

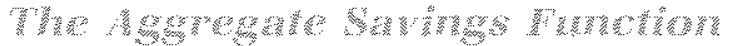

According to equation 1, aggregate savings depends on all of the endowments, both within and across generations, of all of the agents living at time $t$, except those born in period $t-n+1$. In addition, aggregate savings depends on the immediate past interest rate $R(t-1)$, and past savings, while the past savings depended themselves on past interest rates. Therefore, aggregate savings depends also on the past interest rates $R(t-2), \ldots, R(t-n+1)$. But these are not the only variables determining aggregate savings. In analyzing an agent's maximization problem, the choice of a consumption plan at time $t$ will be shown to depend on the agent's endowments from time $t$ to time $t+n-1$, as well as all interest rates from time $t$ to time $t+n-2$. The aggregate savings function can therefore be summarized by saying that it is a function of interest rates and endowments, both within and across the lifetimes of the generations alive at time $t$.

The fact that so many endowments and interest rates enter into the aggregate savings function, coupled with the fact that the aggregate savings function plays a key role, as indicated by equation 4 , seems to make manageable versions of the model unlikely without resorting to sophisticated mathematical machinery. Such a view, while generally correct, is overly pessimistic. Some simplifications can be employed to reduce the complexity of the aggregate savings function.

One starting point is to assume that all generations are alike at birth in that they possess the same set of preferences and the same lifetime endowment patterns. This assumption seems at least superficially reasonable since it is difficult to argue that any two generations, one born right behind the other, would differ importantly in their preferences over available goods or their lifetime productivity profiles, which can be taken as the interpretation of the endowment pattern. In many applications, generations are assumed to be identical.

Another simplifying assumption-one that is somewhat less attractive-is that all agents with in a generation are identical. This does not quite amount to a "representative agent" assumption for the model, because at any point in time there would still be differences among agents, in the sense that some are nearer death than others. In contrast, many representative agent models literally have only one agent who lives forever. Nevertheless, this assumption does reduce the extent of diversity among agents considerably.

In order to make progress in writing out an expression for aggregate savings, then, all agents within a generation are assumed to be identical, and all generations are assumed to be exactly alike in terms of utility functions and endownent patterns. Furthermore, a particular utility function will be employed, namely, a timeseparable logarithmic utility function given by 


$$
\begin{aligned}
U_{t}^{a}\left[c_{t}^{a}(t), \ldots, c_{t}^{a}(t+n-1)\right]= & \ln c_{t}^{a}(t)+\beta \ln c_{t}^{a}(t+1)+\ldots \\
& +\beta^{n-1} \ln c_{t}^{a(t+n-1)}
\end{aligned}
$$

where $\beta>0$ is a discount factor equal to $1 /(1+\delta)$, and $\delta \geq 0$ is the rate of time preference, also known as the discount rate, of the agent.21

Under these assumptions, aggregate savings can be written as $\mathrm{s}^{32}$

$$
\begin{aligned}
S(t)= & \sum_{i=0}^{n-2} \alpha^{t-i} W_{t}(t+i)+\sum_{i=0}^{n-3} \sum_{j=1}^{n-2-i} \alpha^{i-i-j} W_{t}(t+i) \prod_{k=1}^{j} R(t-k) \\
& -\alpha^{i} W_{j}-\sum_{i=1}^{n+2} \sum_{j=0}^{i} \alpha^{i-i} \beta^{j} W_{1-i} \prod_{k=1}^{j} R(t-k)
\end{aligned}
$$

where

$$
W_{k}=\left[\sum_{i=0}^{n+1} \beta^{i}\right]^{-1}\left[W_{i}(t)+\sum_{i=1}^{n-1} W_{i}(t+i) \prod_{j=k-1}^{k+(i-z)} R(t+j)^{-1}\right] \text {. }
$$

Aggregate savings therefore depends on a myriad of endowments and interest rates, as expected. As witten above, it consists of two positive and two negative terms. The discount factor $\beta$ enters only in the negative terms. A convenient feature of this function is that it is linear in the endow. ments $w_{t}(t), w_{t}(t+1), \ldots, w_{t}(t+n-1)$. That is, suitably rearranged, the function can be written as a sum of the endowments with coefficients, and each coefficient can be viewed as having a positive part and a negative part. This fact will now be exploited to interpret the n-period model.

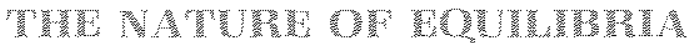

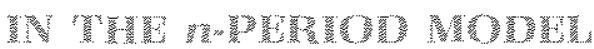

The artificial economy is described compactly by equation 4 , which is

$S(t)=R(t-1) S(t-1)$
As has just been shown, $S(t)$ and $S(t-1)$ are actually complicated functions of interest rates and endowments. The system described by this equation therefore involves interest rates extending into the past as well as expected interest rates extending into the future, but no other variables. If one assumes that agents possess perfect foresight or "rational expectations," expected interest rates can be replaced with actual interest rates, and equation 4 becomes a high-order difference equation in interest rates. Perfect foresight-the assumption that agents can predict with perfect precision the future path of interest rates-is an extreme assumption but is also an important benchmark for solutions under alternative assumptions about how expectations are formed. In the remainder of the paper the perfect foresight assumption will be maintained.

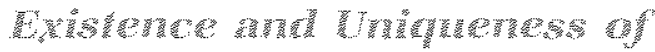

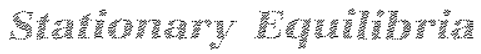

Under the perfect foresight assumption, then, equation 4 can be viewed as a high-order differ. ence equation in interest rates, and stationary solutions will be those where (4) is salisfied and $R(t)=R$ for all $t$. These stationary solutions will be stationary equilibria if they also satisfy the definition of equilibrium given in the previous section. Suppose that the interest rate is constant. Then if $R=\alpha, S(t)=\frac{1}{\alpha} S(t-1)$, so that the system described by (4) has a stationary solution at $P=\alpha$. This stationary solution is one in which fiat currency could have value, provided aggregate savings is positive at that point. $^{23}$ There are also stationary solutions whenever interest rates are constant and $S=0$. These other solutions involve aggregate savings equal to zero and thus could not be equilibria with valued fiat currency. The difference equation that describes the system is of order $2 n-3$; it therefore has as many as $2 n-3$ zeros. Along with the solution at $R=\alpha$, the system has $2 n-2$

\footnotetext{
21 The assumption of time-separable logarithmic utility implies that the goods in the model (actually the same good at different dates) are gross substitutes (roughty, an increase in the price of one good increases the demand for al! other goods) and simplities the discussion of the aggregate savings function without reducing the number of arguments. In the two-period case, gross substitutes implies that savings is an increasing function of the rate of interest. If one relaxes this assumption on the utility function in the two-period model, so that an increase in the rate of interest might lead to less savings by the young, cycles and chaos are possibie (see Grandmont, 1985). An important aspect of this result is that eliminating
}

the gross substitutes assumption still leaves one with an acceptable utility function according to standard theory, so that imposing the assumption, in a sense, is an ad hoc restriction. Kenoe, ef al. (1991) develop al of their general results under the gross substitutes condition and discuss the limitations of the approach at some length.

22 The derivation of this expression is given in appendix 1 . To obtain the aggregate savings function when $n=2$, ignore the second and fourth terms.

23 See equation 2. This is so because $L g$ has been set to zero. 


\section{Table 1}

\section{The Aggregate Savings Function When Interest Rates Are Stationary}

$$
\begin{aligned}
& S(R)= \\
& \left.w_{1}(t)\left[1+\frac{R}{\alpha}+\ldots+\frac{\beta^{n-2}}{\alpha^{n-2}}\right]-\left[\frac{1+\frac{(1+\beta) R}{\alpha}+\frac{\left(1+\beta+\beta^{2}\right) \beta^{2}}{\alpha^{2}}+\ldots+\frac{\left(1+\ldots+\beta^{n-2}\right) R^{n-2}}{\alpha^{n-2}}}{1+\beta+\beta^{2}+\ldots+\beta^{n-1}}\right]\right] \\
& +w_{t}(t+1)\left[1\left[1+\frac{R}{\alpha}+\ldots+\frac{R^{n-3}}{\alpha^{n-3}}\right]-\left[\frac{1+\frac{(1+\beta) R}{\alpha}+\frac{\left(1+\beta+\beta^{2}\right) R^{2}}{\alpha^{2}}+\ldots+\frac{\left(1+\ldots+\beta^{n-2}\right) R^{n-2}}{\alpha^{n-2}}}{R\left(1+\beta+\beta^{2}+\ldots+\beta^{n-1}\right)}\right]\right] \\
& +w_{i}(t+2)\left[\frac{1}{\alpha^{2}}\left[1+\frac{R}{\alpha}+\ldots+\frac{R^{n-4}}{\alpha^{n-4}}\right]-\left[\frac{1+\frac{(1+\beta) R}{\alpha}+\frac{\left(1+\beta+\beta^{2}\right) R^{2}}{\alpha^{2}}+\ldots+\frac{\left(1+\ldots+\beta^{n-2}\right) R^{n-2}}{\alpha^{n-2}}}{R^{2}\left(1+\beta+\beta^{2}+\ldots+\beta^{n-1}\right)}\right]\right] \\
& +w_{t}(t+n-3)\left[\frac{1}{\alpha^{n-3}}\left[1+\frac{B}{\alpha}\right]-\left[\frac{1+\frac{(1+\beta) R}{\alpha}+\frac{\left(1+\beta+\beta^{2}\right) R^{2}}{\alpha^{2}}+\ldots+\frac{\left(1+\ldots+\beta^{n-2}\right) R^{n-2}}{\alpha^{n-2}}}{R^{n-3}\left(1+\beta+\beta^{2}+\ldots+\beta^{n-1}\right)}\right]\right] \\
& +w_{t}(t+n-2)\left[\frac{1}{\alpha^{n-2}}-\left[\frac{1+\frac{(1+\beta) P}{\alpha}+\frac{\left(1+\beta+\beta^{2}\right) \beta^{2}}{\alpha^{2}}+\ldots+\frac{\left(1+\ldots+\beta^{n-2}\right) A^{n-2}}{\alpha^{n-2}}}{R^{n-2}\left(1+\beta+\beta^{2}+\ldots+\beta^{n-1}\right)}\right]\right] \\
& -w_{\mathfrak{f}}(t+n-1)\left[\frac{1+\frac{(1+\beta) R}{\alpha}+\frac{\left(1+\beta+\beta^{2}\right) A^{2}}{\alpha^{2}}+\ldots+\frac{\left(1+\ldots+\beta^{n-2}\right) R^{n-2}}{\alpha^{n-2}}}{R^{n-1}\left(1+\beta+\beta^{2}+\ldots+\beta^{n-1}\right)}\right]
\end{aligned}
$$

"candidate equilibria." It is therefore remarkable that all but two of these can be ruled out as equilibria of the model.

One way to find the zeros is to set $R(t+i)=R$ for every $i$ and find the roots of the resulting high-order polynomial. Such a procedure would normally require numerical techniques since no known analytical method for finding the roots of high order polynomials exists. Considerable progress can be made, however, without explicitly finding all these solutions. To see this, refer to table 1 , which shows the expansion of the aggregate savings function when $R(t)=R$ for all $t$. At the risk of upsetting the notation some. what, this function will be denoted $S(R)$.

Any zero of $S(R)$ that involves a negative stationary interest rate is not an equilibrium of the model, so attention can be restricted to $R>$
0. If aggregate savings is strictly increasing in stationary interest rates $R>0$, then there can be at most one zero of the aggregate savings function for $R>0$. It turns out that this is indeed the case. First, consider $S(R)$ as $R$ approaches zero from the positive side. Inspection of table 1 shows that this limit is negative infinity. Next, consider $S(R)$ as $R$ becomes very large. The limit in this case is positive infinity. Thus, $S(R)$ tends to increase with increases in $R$. It may, however, decrease over some ranges of $R$. Fo show that this is not the case, consider the derivative of $S(R)$ with respect to $R$, which is given in appendix 2 . This derivative is always positive, and thus aggregate savings is strictly increasing in stationary interest rates $R>0$.

The above argument is summarized in figure 1 , which shows a graph of $S(R)$ against $R$. Since 


\section{Figure 1 \\ The Existence of Steady-State Equilibria}

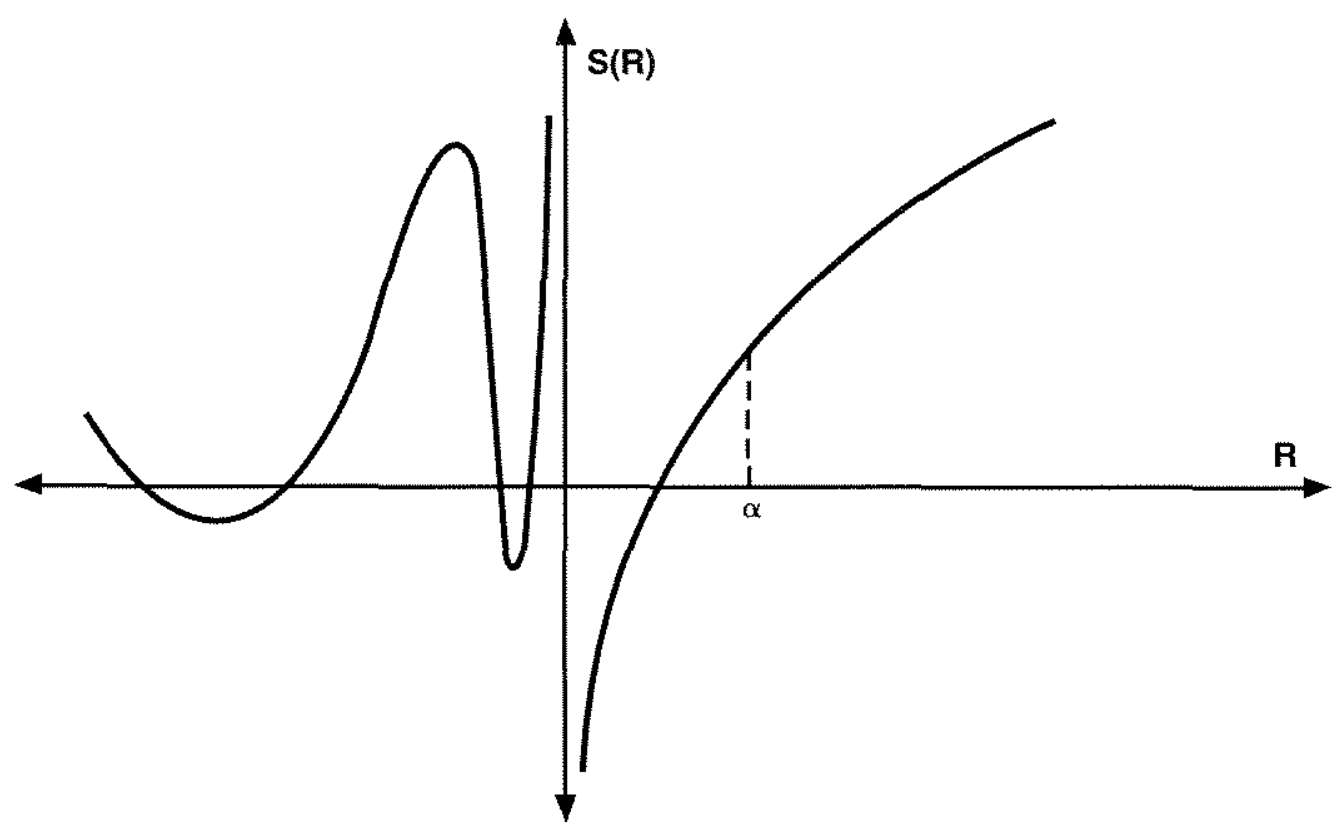

$S(R)$ is strictly increasing in $R$, for $R>0$, only one of the zeros of the aggregate savings function can occur at a point where the interest rate is positive. All $2 n-4$ of the remaining zeros, if they exist, must occur at points where the interest rate is negative. Therefore, exactly one stationary equilibrium exists in this model where $S=0$. A second equilibrium, a stationary monetary equilibrium, may exist if aggregate savings is positive when $R=\alpha$. This condition is the subject of the next portion of the paper.

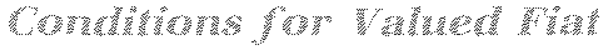

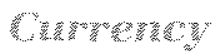

In the system described by equation 4 , there is always a candidate equilibrium at $R=\alpha$. If savings is positive at this steady state, then fiat currency has positive value, and the definition of equilibrium is satisfied. The condition for fiat currency to be valued in equilibrium in this model is therefore found by evaluating $S(R)$ at $R=\alpha$ and comparing the result to zero. When there is no population growth $(\alpha=1)$ and no dis- counting $(\beta=1)$, this condition is

(5) $\sum_{i=1}^{n} w_{1}(t+i-1)\left[(n-i)-\frac{(n-1)}{2}\right]>0$.

As an example, let $n=2$. Then the condition for valued fiat currency is that $w_{i}(t)>w_{t}(t+1)$, which is a standard result from analogous wo period lifetime models.

The condition given in inequality 5 is simple and symmetric. Endowments received in the first half of agents' lives contribute positively to satisfying the condition, while endowments received in the second half detract from that satisfaction. The endowment receiving the largest weight is the one received by agents in their first period of life, $w_{t}(t)$, and the weights fatl linearly with the endowments received in later periods of life. The weight on the endowment received in the last period of life, $w_{i}(t+n-1)$, is the smallest (it is a large negative weight). The endowment received by agents at the midpoint of their lives receives zero weight in the condition. 


\section{Figure 2}

\section{An Endowment Pattern with Valued Money}

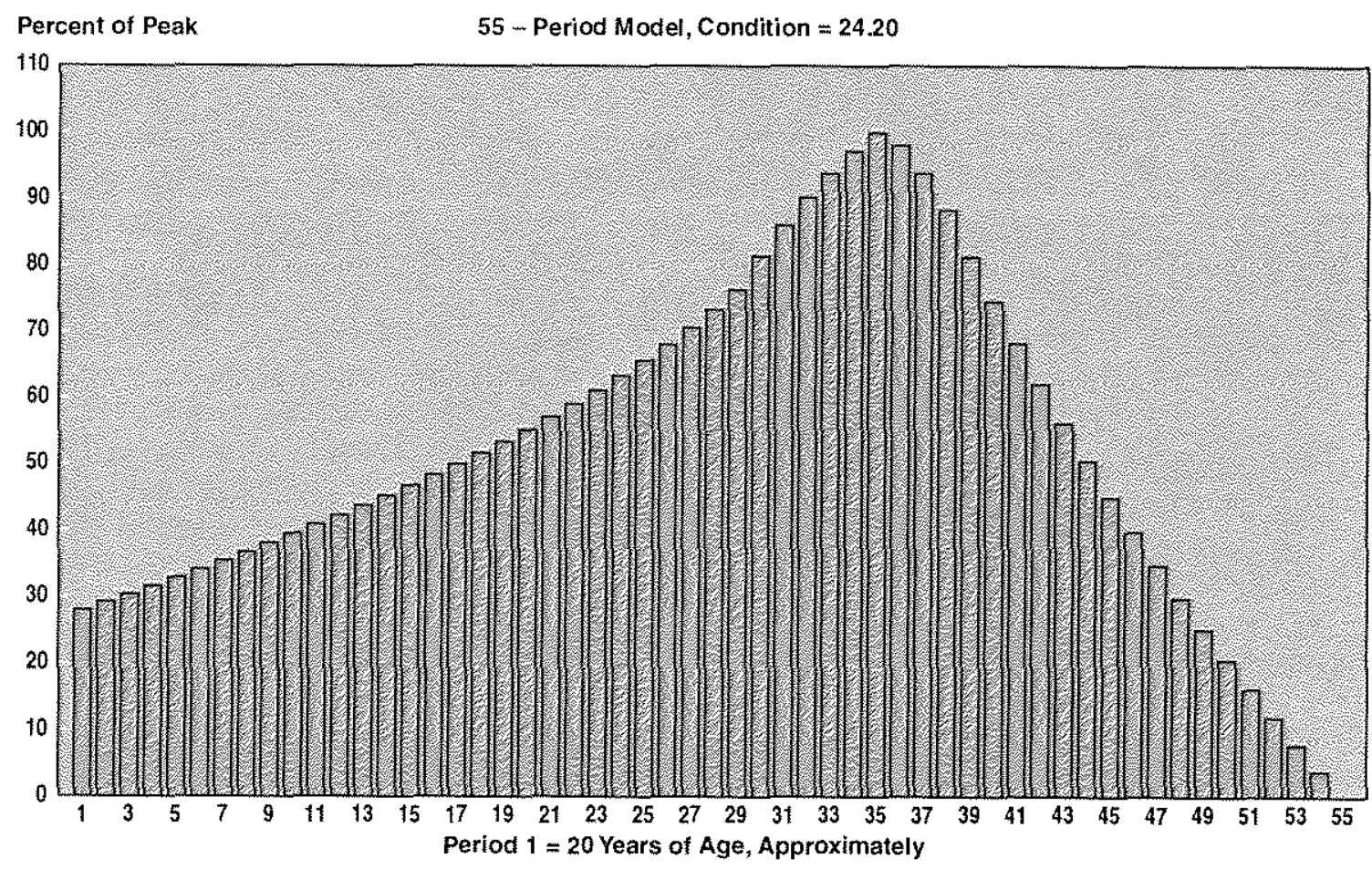

A common criticism of the two-period overlapping generations model is that the condition for valued fiat currency is $w_{i}(t)>w_{i}(t+1)$, which implies declining endowments through an agent's lifetime. If the endowment stream is interpreted as a lifetime productivity profile, most economists would have hump-shaped patterns in mind to represent the empirical reality. Productivity is low when people first enter the work force but rises steadily through life before dropping off sharply at retirement. The condition for valued fiat currency in the $n$ period model can in fact accommodate the hump-shaped endowment pattern many have in. mind. In figure 2 , an illustrative case is presented, where, in a 55 -period model, the condition for valued fiat currency is met and the lifetime endowment pattern is plausibly hump-shaped.

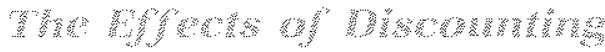

Both the discount factor $\beta$ and the gross rate of population growth $\alpha$ have a role to play in the condition for valued fiat currency. First, consider the situation in which agents discount the future $(\beta<1)$, but in which there is no population growth. Results due to Aiyagari $(1988,1989)$ suggest that, if the number of periods is large ( $n$ is large), fiat currency camnot be valued in equilibrium in this situation. As mentioned in the introduction, this is a rather negalive conclusion, since most economists believe that people do discount the future. It is therefore important to see that discounting does not play such a large role, even when $n$ is large.

The condition in this case is

(6) $\sum_{i=1}^{n} w_{i}(t+i-1)[(n-i)-B]>0$

where

$B=\frac{1+(1+\beta)+\left(1+\beta+\beta^{2}\right)+\ldots+\left(1+\beta+\beta^{2}+\ldots+\beta^{n-2}\right)}{1+\beta+\beta^{2}+\ldots+\beta^{n-1}}$ 


\section{Table 2}

Values of $B$ When $n$ Is Large, Choosing $\beta$ Appropriately

\begin{tabular}{lcrrc} 
& Appropriate $\beta$ & Value of $B$ & $B$ if $\beta=1$ & Percentage increase \\
$n=2$ & .54 & .65 & .5 & $30.0 \%$ \\
$n=10$ & .86 & 5.71 & 4.5 & 26.9 \\
$n=30$ & .95 & 18.35 & 14.5 & 26.6 \\
$n=55$ & .97 & 34.14 & 27.0 & 26.4 \\
$n=220$ & .9926 & 138.36 & 109.5 & 26.4 \\
$n=660$ & .9975 & 416.28 & 329.5 & 26.3 \\
\hline
\end{tabular}

The effects of discounting can be found by considering $B$, since $\beta$ enters the condition only through this term. When $\beta=1$, this ratio of sums is $(n-1) / 2$. When $\beta<1$, the present case, the value of $B$ will be greater than $(n-1) / 2$, and one can immediately conclude that discounting will make the condition for valued fiat currency more difficult to satisfy than if there were no discounting.

When $\beta=0$, which represents the extreme case in which agents discount the future completely and care only about today's consumption, the value of $B$ is $n-1$. An examination of inequality 6 shows that all the weights on all the endowments would be less than of equal to zero in this case, and thus that the condition for valued fiat currency could never be satisfied, no matter what the endowment pattern. This faet is important because, for values of $\beta$ between zero and one, $B$ tends to $n-1$ when $n$ is large. Hence, a version of Aiyagari's (1988) result is illustrated: if $n$ is large enough and agents discount the future, fiat money cannot have value in equilibrium. There is more to this condition, however.

In particular, the similarity between the extreme case of complete discounting $(\beta=0)$ and the case of some discounting $(\beta$ between zero and one) with $n$ large is not accidental.

In the overlapping generations model, $n$ periods constitute a human lifetime. When $n$ is made larger and larger, the lifetime is measured in smaller and smaller units of time. In fact, one motivation for considering $n$-period overlapping generations models was to get to a lime period that could be interpreted as a quarter or a month. The discount factor $\beta$ is therefore not independent of $n$. Keeping $\beta$ fixed and allowing $n$ to approach infinity has the same effect as letting $\beta$ approach zero. Some simple calculations bear this fact out.

The discount factor $\beta$ is equal to $1 /(1+\delta)$, where $\delta$ is the discount rate. Many economists think the annual discount rate is about .03 , so that $\beta$ would be about .97 . But this is only on an annual basis; on a quarterly or monthly basis, a new value of $\beta$ must be calculated. Otherwise, one would be saying that people discount the future at a rate of 3 percent per quarter or 3 percent per month-in other words, at a much more rapid rate. In the limit, a discount rate of 3 percent per day or hour or minute would be implied. Agents would be discounting the future completely. This is why letting $n$ become large with a fixed $\beta<1$ approximates the case where $\beta=0$.

Table 2 shows values of $B$ for various values of $n$ when $\beta$ is chosen to appropriately reflect the length of a time period implied by the choice of $n$. The case of $n=55$ is taken to represent a model where a time period is a year, and hence the discount factor is set at .97 . Other values of $\beta$ are chosen relative to this standard, so that $n=220$ represents a quarterly model and $n=660$ represents a monthly model. Values of $n$ less than 55 involve time periods longer than a year. The second column in the table shows the value of $B$ under discounting, while the third column shows the value of $B$ for the nodiscounting case $(\beta=1)$. The final column shows the increase in $B$ due to discounting. Since $B$ represents a negative part in the condition. for fiat currency to be valued (see inequality 6 ), the figures in the final column give some sense of the effect of discounting on the condition for valued fiat currency. In particular, $B$ is about 26 percent larger under discounting than it is in the no-discounting case, as $n$ gets large. 
Remarkably, smaller values of $n$ overstate this effect, so that in models with large $n$ it is actually somewhat easier to meet the condition for valued fiat currency.

According to the inequality in $(6), B$ affects all of the endowments equally. The weight on the endowment that agents receive in the first period of their lives, $w_{1}(t)$, is still positive, although less so than in the no-discounting case. Similarly, the weight on the endowment that agents receive in the last period of life is now more negative. In fact, the weights still decline linearly with endowments received in later periods of life, but the point at which the weight on an endowment is zero occurs, not at midlife, but somewhat before midlife. Hence, the endowment pattern will have to involve larger endowments earlier in life if fiat currency is to have value, relative to the no-discounting case. In terms of hump-shaped endowment patterns, the peak endowment would have to occur eartier in an agent's lifetime.

In summary, while discounting makes the con dition for valued fiat currency more stringent, this effect has a limit once it is recognized that the discount rate is not independent of the number of periods in this model.

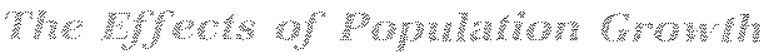

It has long been recognized in research on overlapping generations models of money that including population growth tsometimes inter* preted as a model in which the economy is growing) mitigates the effects of discounting on the condition for valued fiat currency. In fact, in the two-period case, these effects cancel exactly when the discount rate is equal to the rate of population growth that is, when $\beta=\alpha^{-1}$ ). Of course, because the time period in this model is a fraction of a human lifetime, population growth rates, like discount rates, are not independent of $n$.

In the present model with $n$ periods, the condition for valued fiat carrency when both population growth $(\alpha>1)$ and discounting $(\beta<1)$ are allowed is given by

(7) $\sum_{i=1}^{n} w_{t}(t+i-1) \alpha^{1-i}[(n-i)-B]>0$

Thus, the weight on the endowment received by agents in the first period of their lives is unchanged relative to the case with no population growth, but the weights on endowments received in successive periods are reduced by ever greater powers of $\alpha$. Since interest centers on the case in which population is growing, $\alpha$ $>1$, and since the endowments received in the middle and later periods of life receive negative weights, one conclusion is that allowing population growth makes it somewhat easier to satisfy the condition for valued flat currency.

In a special situation, the negative effects of discounting and the positive effects of population growth on the condition for valued fiat currency cancel out exactly. In particular, if all of the endowments received by agents in each period of their lives are exactly equal, then the condition for valued fiat curreney when $\beta=\alpha^{-1}$ is the same as the condition when $\beta=\alpha=1$. In other words, setting the population growth rate equal to the discount rate produces no net effects only in the special case when the endow ment stream is constant. The details of this argument are given in appendix 3. This result is a small departure from standard results for the two-period model. When $n=2$, the condition for valued fiat currency is $\alpha \beta w_{i}(t)>w_{i}(t+1)$, so that setting the rate of population growth equal to the discount rate always produces exactly off. setting effects, regardless of the endowment pattern. This effect generalizes to the $n$-period case only when all the endowments are equal.24

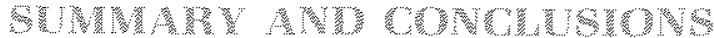

Samuelson's model of money, which has generally been formulated in terms of two period lifetimes, is often criticized as being un-

\footnotetext{
2A One final comment is appropriate on the condition for fiat currency to have value. Avyagari (1989) has clamed that the intertemporal elasticity of substitution is important and must be larger than one for fiat curfency to have value if the discount rate is less than the rate of population growth (and $n$ is large). In the present example with logarithmic utility, the elasticity of substitution is constant and equal to unity. But it is still a simple matter to find plausible endow. ment patterns that will permit fiat currency to have value.
} 
realistic, since a time period in the model is on the order of 25 years. A basic version of an $n$-period model is investigated in this paper. The key assumptions are that agents are identical within and across generations, and that they possess time-separable logarithmic utility functions. The fact that agent lifetimes are divided into $n$ periods instead of two periods induces a complicated aggregate savings function that depends on a plethora of interest rates and endowments.

Although the economy analyzed in this paper, assuming agents possess perfect foresight, is characterized by a high-order difference equation which has $2 n-2$ candidate stationary equilibria, there are at most two stationary equilibria of the model. Furthermore, these stationary equilibria are the same two, the autarkic equilibrium and the monetary equilibrium, that may exist in the two-period model. The welfare properties of these equilibria were not analyzed.

The condition for fiat currency to have value in the $n$-period case allows for plausibly humpshaped endowment patterns. When the agents in the model discount future consumption, the condition for valued fiat currency becomes more difficult to meet. There is a limit to this effect, however, and monetary steady states can exist even when the number of periods in the model is large. An allowance for population growth makes the condition for valued fiat currency easier to meet. These results, taken together, suggest that Samuelson's framework, at least in a broad sense, is robust to extensions in the number of time periods in the model.

At least four central concerns about Samuelson's model of money are distinct from, and perhaps more important than, the time period problem addressed in this paper. The first is that the analysis in this paper places heavy reliance on the arbitrage condition which equated rates of return across alternative assets. In actual economies, money is dominated in rate of return by alternative risk-free assets. A second central concern is that the role of storage has not been considered. In addition, the agents in this model do not leave bequests to future generations. Finally, production has not been considered. These deficiencies require remedies and extensions other than those discussed here.

Finally, it is perhaps useful to distinguish the interpretation of the $n$-period model used in this paper from interpretations based on the idea of "long-lived agents." In some research, agents with two-period lifetimes have been viewed as living a short time, and n-period models, letting $n$ approach infinity, have been regarded as approximations to models with agents who possess infinite planning horizons. In the interpretation offered in the present paper, the agents in the model do not really live any longer, their lifetimes are just divided up into smaller fragments.

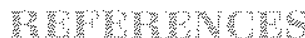

Alyagari, S. Rao. "Can There Be Short-Period Deterministic Cycles When People are Long Lived?" Quarterly Journal of Economics (February 1989), pp. $163-85$.

"Nonmonetary Steady States in Stationary Overlapping Generations Models with Long Lived Agents and Discounting: Multiplicity, Optimality, and Consumption Smoothing," Journal of Economic Theory (June 1988), pp. 102-27.

Altig, David, and Chartes T. Carlstrom. "Inflation, Personal Taxes, and Real Output: A Dynamic Analysis," Journal of Money, Credit and Banking, Part 2 (August 1991), pp. 547-71.

Alerbach, Alan J., and Laurence J. Kotlikoff. Dynamic Fiscal Policy (Cambridge University Press, 1987).

Becker, Robert A., and Ciprian Foias. "A Characterization of Ramsey Equitibrium," Joumal of Economic Theory (February 1987), pp. 173-84.

Blanchard, Olivier J. "Debt, Deficits, and Finite Horizons," Journal of Political Economy (April 1985), pp. 223-47.

Brock, W. A. "Overlapping Generations Models with Money and Transactions Costs," in Benjamin M. Friedman and Frank H. Hahn, eds., Handbook of Monetary Economics, Volume I (North-Holland, 1990).

Friedman, Benjamin M., and Frank H. Hahn. "Preface to the Handbook," in Benjamin M. Friedman and Frank H. Hahn, eds., Handbook of Monetary Economics, Volume I (NorthHolland, 1990).

Geanakoplos, John. "Overlapping Generations Model of General Equilibrium," in John Eatwell, Murray Milgate, and Peter Newman, eds., The New Palgrave: General Equilibrium (W. W. Norton, 1989).

Grandmont, Jean-Michel. "On Endogenous Competitive Business Cycles," Econometrica (September 1985), pp. 995-1045.

Kehoe, Timothy J., David K. Levine, Andreu Mas-Colell, and Michael Woodford. "Gross Substitutability in Large Square Economies:" Journal of Economic Theory (June 1991), pp. $1-25$.

Kydland, Finn E., and Edward C. Prescott. "Time to Build and Aggregate Fluctuations," Econometrica (November 1982), pp. 1345.70 .

McCallum, Bennett $T$. "The Role of Overfapping-Generations Models in Monetary Economics," Carnegie-Rochester Conference Series on Public Policy (Spring 1983), pp. 9.44. 
McCandless, George T. Jr., and Neil Wallace. Introduction to Dynamic Macroeconomic Theory: An Overlapping Generations Approach (Harvard University Press, 1991).

Ramsey, Frank "A Mathematical Theory of Saving," Economic Journal (December 1928), pp. 543-59.

Reichlin, Pietro. "Endogenous Cycles with Long-Lived Agents," Journal of Economic Dynamics and Control (April 1992), pp. 243-66.

Rios-Rull, José Victor. "Life Cycle Economies and Aggregate Fluctuations," Carnegie-Mellon Working Paper (June 1991).

Samuelson, Paut A. "An Exact Consumption-Loan Model of Interest With or Without the Social Contrivance of Money," Journal of Political Economy (December 1958), pp. 467-82.

Sargent, Thomas J. Dynamic Macroeconomic Theory (Harvard University Press, 1987).
Sims, Chris "Comment," in Hugo F. Sonnenschein, ed., Models of Economic Dynamics (Springer-Verlag, 1986)

Solow. Robert M. "A. Contribution to the Theory of Economic Growth," Quarterly Joumal of Economics (February 1956), pp. $65-94$.

Tobin, James. "Discussion," in John $\mathrm{H}$. Kareken and Neil Wallace, eds. Models of Monetary Economies (Federal Reserve Bank of Minneapolis, 1980), pp. 83-90.

Wallace, Neil. "The Overlapping Generations Model of Fiat Money," in John H. Kareken and Neil Wallace, eds. Models of Monetary Economies (Federal Reserve Bank of Minneapolis, 1980), pp. 49-82.

Woodford, Michael. "Imperfect Financial Intermediation and Complex Dynamics," in William A. Barnett, John Geweke, and Karl Shell, eds, Economic Complexity: Chaos, Sunspots, Bubbles, and Nonlinearity (Cambridge University Press, 1989).

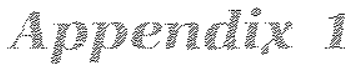

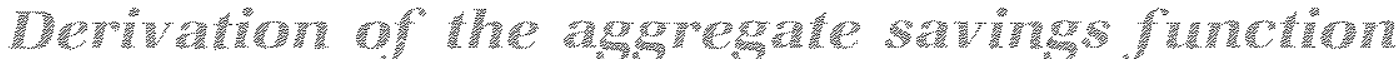

Denoting $l^{n}(t)$ as the amount of one-period loans made by agent a of generation $t$ at date $t$, an individual agent faces the following problem assuming $n$ is large:

$\operatorname{Max} u_{t}^{a t}\left[c_{t}^{a}(t), C_{t}^{a}(t+1), \ldots, c_{t}^{a}(t+n-1)\right]$

subject to

$c_{i}^{a}(t)+T_{t}^{3}(t) \leq w_{t}^{a}(t)$

$c_{i}^{a}(t+1)+l_{t}^{a}(t+1) \leq w_{t}^{a}(t+1)+R(t) l_{t}^{a}(t)$

$c_{t}^{a}(t+2)+l_{t}^{a}(t+2) \leq w_{t}^{a}(t+2)+R(t+1) l_{t}^{a}(t+1)$

$c_{t}^{a}(t+n-2)+l_{t}^{a}(t+n-2) \leq w_{t}^{a}(t+n-2)$

$+P(t+n-3) l_{t}^{2}(t+n-3)$

$c_{f}^{a}(t+n-1) \leq w_{i}^{a}(t+n-1)+R(t+n-2) I_{t}^{i}(t+n-2)$.

The constraints in this problem can be written more concisely by eliminating $l_{r}^{a}$, which yields

$$
\begin{aligned}
& c_{i}^{a(t)}+\sum_{i=1}^{n-1} c_{i}^{a}(t+i) \prod_{j=0}^{i-1} R(t+j)^{-1} \leq w_{i}^{a}(t) \\
& +\sum_{i=1}^{n-1} w_{i}^{a}(t+i) \prod_{j=0}^{i-1} R(t+j)^{-1} .
\end{aligned}
$$

For the logarithmic utility function given in the text, the firsturder conditions are given by

$$
\begin{gathered}
c_{t}^{a}(t)^{-1}=\mu \\
c_{t}^{a}(t+1)^{-1}=\mu \beta^{-1} R(t)^{-1} \\
c_{t}^{a}(t+2)^{-1}=\mu \beta^{-2}[R(t) R(t+1)]^{-1} \\
\vdots \\
c_{t}^{a}(t+n-2)^{-1}=\mu \beta^{2 \cdots n} \prod_{j \pi n}^{n-3}\left[(t+j)^{-1}\right. \\
c_{t}^{a}(t+n-1)^{-1}=\mu \beta^{1-n} \prod_{j=0}^{n-2}\left[(t+j)^{-1} .\right.
\end{gathered}
$$

These first-order conditions can be combined into the budget constraint to yield

$c_{t}^{a}(t) \sum_{i=0}^{n-1} \beta^{i}=w_{i}^{a}(t)+\sum_{i=1}^{n-1} w_{i}^{a}(t+i) \prod_{j=0}^{i-1} R(t+j)^{-1}$

To construct an expression for aggregate savings, define

$W_{k}^{a}=\left[\sum_{i=0}^{n-1} \beta^{i}\right]^{-1}\left[w_{i}^{a}(t)+\sum_{i=1}^{n+1} w_{t}^{a}(t+i) \prod_{j=k-1}^{k+(i-2)} R(t+j)^{-1}\right]$ 
which is equal to $c(t)$ when $k=1$. The savings of agent a period by period can be written as

$$
\begin{gathered}
I_{t}^{a}(t)=w_{t}^{a}(t)-C_{t}^{a}(t) \\
I_{t}^{a t}(t+1)=w_{t}^{a}(t+1)+R(t) l_{t}^{a}(t)-c_{t}^{a}(t+1) \\
I_{t}^{a}(t+2)=w_{t}^{a}(t+2)+R(t+1) l_{t}^{a}(t+1)-c_{t}^{a}(t+2) \\
\vdots \\
I_{t}^{a}(t+n-3)=w_{t}^{a}(t+n-3)+R(t+n-4) l_{t}^{a}(t+n-4) \\
-c_{t}^{a}(t+n-3) \\
l_{t}^{a}(t+n-2)=w_{t}^{a}(t+n-2)+R(t+n-3) l_{t}^{a}(t+n-3) \\
-c_{t}^{a}(t+n-2) .
\end{gathered}
$$

The savings of agent a can be defined in terms of $W_{1}^{a}$ by recursive substitutions as

$$
\begin{aligned}
& l_{i}^{a}(t)=w_{t}^{a}(t)-W_{i}^{a t} \\
& l_{t}^{a}(t+1)=w_{t}^{a}(t+1)+R(t) w_{i}^{a}(t)-(1+\beta) R(t) W_{1}^{a} \\
& l_{t}^{a}(t+2)=w_{i}^{a}(t+2)+R(t+1) w_{i}^{a}(t+1)+R(t+1) R(t) w_{i}^{a}(t) \\
& -\left(1+\beta+\beta^{2}\right) R(t) R(t+1) W_{1}^{a} \\
& l_{i}^{a}(t+n-2)=w_{i}^{a}(t+n-2)+R(t+n-3) w_{x}^{2}(t+n-3) \ldots \\
& +w_{i}^{a}(t) \prod_{j=0}^{n-3} R(t+j)-\left(1+\beta+\ldots+\beta^{n-2}\right) W_{1}^{a} \prod_{j=0}^{n-3} R(t+j) .
\end{aligned}
$$

Since all agents are the same, these equations represent the savings of every agent in the economy over the life of the agent. By backdating these loan amounts to time $t$, a set of loan amounts can be found that describes the savings of each generation held at time t. Here the assumption of identical endowment profiles, which implies that, for instance, $w_{t}^{a}(t+1)=w_{t-1}^{a}(t)$, is employed. Back-dating therefore implies

$$
\begin{aligned}
& I_{t}^{a}(t)=w_{t}^{a}(t)-W_{1}^{a} \\
& l_{t-1}^{a}(t)=w_{t}^{a}(t+1)+R(t-1) w_{t}^{a}(t)-(1+\beta) R(t-1) W_{0}^{a} \\
& I_{\ell-2}^{a}(t)=w_{t}^{a}(t+2)+R(t-1) w_{t}^{a}(t+1) \\
& +R(t-2) R(t-1) w_{t}^{a}(t)-\left(1+\beta+\beta^{2}\right) R(t-2) R(t-1) W_{-1}^{a t} \\
& \vdots \\
& I_{t-n+2}^{a}(t)=w_{t}^{a}(t+n-2)+R(t-1) w_{1}^{a}(t+n-3)+\ldots \\
& \quad+w_{t}^{a}(t) \prod_{j=1}^{n=2} R(t-j) \\
& \quad-\left(1+\beta+\ldots+\beta^{r-2}\right) W_{3-n}^{a} \prod_{j=1}^{n-2} R(t-j) .
\end{aligned}
$$

Aggregate savings is the sum of these amounts, weighted appropriately for the number of agents in each generation. Since the gross rate of population growth, $\alpha$, is constant, the generation born at date $t-1$ is always smaller by a factor of $1 / \alpha$ relative to the generation born at date $t$. Normalizing population of the date $t=0$ generation to one yields the following expression for aggregate savings $(n \geq 3)$ :

$$
\begin{aligned}
S(t) & =\sum_{i=0}^{n-2} \alpha^{t-i} W_{i}(t+i)+\sum_{i=0}^{n+3} \sum_{j=1}^{n+2-i} \alpha^{t-i-j} W_{1}(t+i) \prod_{k=1}^{i} R(t-k) \\
& -\alpha^{t} W_{1}-\sum_{i=1}^{n-2} \sum_{j=1}^{i} \alpha^{i-i} \beta^{j} W_{1-i} \prod_{k=1}^{i} R(t-k)
\end{aligned}
$$

as given in the text.

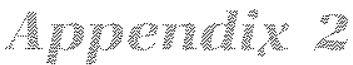

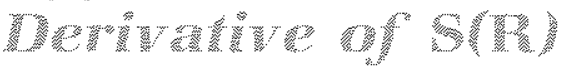

The derivative is given by

$$
\begin{aligned}
& \frac{d S}{d R}=w_{t}(t)\left[\frac{1}{\alpha}+\frac{2 R}{\alpha^{2}}+\frac{3 R^{2}}{\alpha^{3}}+\ldots+\frac{(n-2) R^{n-3}}{\alpha^{n-2}}-\left[\frac{(1+\beta)}{\frac{\alpha}{\alpha}+\frac{\left(1+\beta+\beta^{2}\right) 2 R}{\alpha^{2}}+\ldots+\frac{\left(1+\beta+\ldots+\beta^{n-2}\right)(n-2) h^{n-3}}{\alpha^{n-2}}}\right]\right] \\
& +w_{i}(l+1)\left[\frac{1}{\alpha^{2}}+\frac{2 R}{\alpha^{3}}+\frac{3 R^{2}}{\alpha^{4}}+\ldots+\frac{(n-3) R^{n-4}}{\alpha^{n-2}}+\frac{1}{R^{2} \sum_{i=1}^{i n-1} \beta^{i}}-\left[\frac{\left[\left(1+\beta+\beta^{2}\right)\right.}{\alpha^{2}}+\frac{\left(1+\beta+\beta^{2}+\beta^{3}\right) 2 R}{\alpha^{3}}+\ldots+\frac{\left(1+\beta+\ldots+\beta^{n+2}\right)(n-3) R^{n-4}}{1+\beta+\beta^{2}+\ldots+\beta^{r n-1}}\right]\right] \\
& +w_{i}(t+2)[.]+\ldots-w_{t}(t+n-1)[.] .
\end{aligned}
$$


By inspection, it is apparent that potentially negative portions of this derivative are offset by larger positive terms. For instance, the term $\frac{-\left(1+\beta+\beta^{2}\right) 2 R w_{t}^{(t)}}{\alpha^{2}}\left[\sum_{i=0}^{n-1} \beta^{j}\right]^{-1}$ is offset by the positive term $2 R w_{i}(t) / \alpha^{2}$. Hence, the derivative is positive.

Appendix 3

\section{When Do Discounting pofects Dxacty Offset

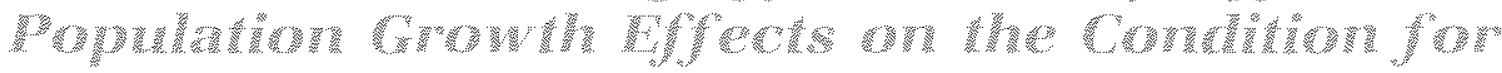 Valned Fint Curternoy?}

When the endowments received by agents in each period are equal, setting $\beta=\alpha^{-3}$ implies no net ef fect on the condition for valued fiat currency. Equal endowments implies that the condition is $\sum_{i=1}^{n} \alpha^{1-i}[(n-i)-\mathrm{B}]>0$.

If this sum is exactly zero, it would be equivalent to the condition with no discounting and no population growth, that is, $\alpha=\beta=1$. The sum is exactly zero when $\beta=\alpha^{-1}$. To see this, write the sum as

$$
\begin{gathered}
{\left[(n-1)+\frac{(n-2)}{\alpha}+\frac{(n-3)}{\alpha^{2}}+\ldots+\frac{1}{\alpha^{n-2}}\right]} \\
-B\left[1+\frac{1}{\alpha}+\frac{1}{\alpha^{2}}+\ldots+\frac{1}{\alpha^{n-2}}\right]>0 .
\end{gathered}
$$

The term multiplying $B$ cancels with the denominator of $B$ (see the text) when $\beta=\alpha^{-1}$. The first sum is simply the numerator of $B$ when $\beta=\alpha^{\prime \prime 1}$. Hence, this sum is zero when $\beta=\alpha^{-1}$. 